УДК 532.5: 536.24

\title{
ЗАСТОСУВАННЯ МЕТОДУ ГРАТОК БОЛЬЦМАНА ДО АНАЛІЗУ ТЕЧІЇ НАНОРІДИНИ В КАНАЛІ МІЖ КОАКСІАЛЬНИМИ ЦИЛІНДРАМИ
}

\author{
Авраменко А.О., чл.-кор. НАН України, Тирінов А.І., канд. техн. наук, \\ Дмитренко Н.П., канд. техн. наук, Кравчук О.В.
}

Інститут технічної теплофізики НАН України, вул. Желябова 2a, м. Київ, 03068, Україна

Досліджено потік ТейлораКуетта нанорідин в криволінійному каналі, що утворений двома концентричними циліндричними поверхнями. Рух потоку забезпечувався обертанням внутрішньої циліндричної поверхні. Було вивчено вплив наступних параметрів на критичні значення числа Тейлора: відношення радіусів опуклих i увігнутих стін, безрозмірних параметрів, що описують температурний градієнт, відносну щільність наночастинок, співвідношення броунівської дифузії і термофорезу, а також чисел Прандтля і Шмідта.
Исследовано течение ТейлораКуетта наножидкостей в криволинейном канале, образованном двумя концентрическими цилиндрическими поверхностями. Движение потока обеспечивалось вращением внутренней цилиндрической поверхности. Было изучено влияние следующих параметров на критические значения числа Тейлора: отношение радиусов выпуклых и вогнутых стен, безразмерных параметров, описывающих температурный градиент, относительную плотность наночастиц, соотношение броуновской диффузии и термофореза, а также чисел Прандтля и Шмидта.
Taylor-Couette flow of nanofluids in curved channel, which is formed by two concentric cylindrical surfaces, is investigated. The flow is moved by rotating the inner cylindrical surface. It is analyzed the influence of following parameters on the critical Taylor numbers: the ratio of the radii of convex and concave walls, dimensionless parameters describing the temperature gradient, the relative density of nanoparticles, the ratio of Brownian diffusion and thermophoretic diffusion, Prandtl and Schmidt numbers.

Бібл. 19, рис. 1, табл. 1.

Ключові слова: нанорідина, відцентрова нестійкість, криволінійний канал, тепло- масообмін, потік Тейлора-Куетта.

$c$ - теплоємність;

$D$ - коефіцієнт дифузії;

$k$ - теплопровідність нанорідини;

$R$ - радіус циліндричної поверхні;

$T$ - температура;

$u$ - швидкість потоку;

$\alpha$ - коефіцієнт теплового об'ємного розширення;

$\mu$ - коефіцієнт динамічної в'язкості;

$\rho$ - щільність;

$\phi$ - концентрація наночастинок.

\section{Bcmyn}

Унікальні властивості нанорідин, і в першу чергу їх здатність підсилювати тепловіддачу, привертають пильну увагу дослідників. Найбільш важливими із них є висока теплопровідність нанорідин і їх низька чутливість до седиментації, ерозії і засмічення, які відбуваються у звичайних рідинах з домішками мікрочастинок [1]. У

\section{Індекси:}

1 - внутрішній циліндр;

2 - зовнішній циліндр;

$B$ - броунівська дифузія;

$f$ - рідина;

$p$ - наночастинки;

$T$ - термофорез.

Безрозмірні комплекси:

$\Theta=\frac{T-T_{1}}{T_{2}-T_{1}} ; \quad U=\frac{u}{u_{1}}$.

зв'язку з цим можна навести багато важливих областей застосування нанорідин, наприклад, атомна енергетика, теплове управління охолодженням електронних і оптичних пристроїв, мікротеплові труби та наноструктуровані матеріали і складні рідини [1-3].

В останні роки підвищення тепловіддачі в нанорідинах одно- і двофазних потоків інтен- 
сивно вивчалося як експериментально [4-6] так і теоретично [7-11].

Для створення та стабілізації нанорідин використовуються різні методи i, зокрема, відцентровий метод [12, 13]. При цьому нанорідини піддаються впливу відцентрової нестійкості різної природи. Один 3 таких типів нестійкості це вихори Тейлора, виникнення яких залежить не тільки від відцентрової сили, але також може визначатися температурними $\mathrm{i}$ концентраційними полями.

Вплив градієнта температури на потоки Тейлора-Куетта були вивчені в серії робіт [14-16]. Була виведена проста формула для критичної швидкості. В [15] зазначалося, що в потоці Куетта параметри полів течії і спіральних вихорів, кут спіралі і розмір спіральних вихорів збільшуються зі збільшенням числа Річардсона. Автори [16] провели моделювання потоку в невеликому зазорі між коаксіальними циліндрами при різних температурах. Вони показали наявність вихорів Тейлора разом $з$ іншими ефектами залежно від плавучості.

Мета даної роботи полягає у вивченні гідродинаміки та тепло- i масообміну у зазорі течії нанорідини в криволінійному каналі, утвореному двома концентричними циліндричними поверхнями 3 внутрішній поверхнею, що обертається, а також відцентрової нестійкості.

Моделювання явищ переносу в потоці нанорідини потребує також розгляду рівняння для концентрації наночастинок 3 урахуванням броунівської дифузії та термофорезу. Крім того, ці ефекти мають бути включені також в рівнянні енергії. У даній роботі всі вищезгадані ефекти враховуються.

\section{Метод розрахунку}

Для дослідження гідродинаміки, тепло- i масообміну та визначення критичного числа Тейлора був вибраний метод решіток Больцмана (LBM-Lattice Boltzmann Method). Даний метод докладно описаний в $[17,18]$. Значення критичного числа Тейлора визначалось за параметрами течії в момент виникнення іiі нестабільності.

Метод решіток Больцмана базується на дискретних рівняннях Больцмана в BGK-наближенні [19] (Bhatnagar-Gross-Krook).

$$
\begin{aligned}
& \frac{\partial f_{v}}{\partial t}+v_{i} \cdot \frac{\partial f_{v}}{\partial x_{i}}=\frac{1}{\tau}\left(f_{v}^{e}-f_{v}\right)+R_{v}, \\
& \frac{\partial f_{T}}{\partial t}+v_{i} \cdot \frac{\partial f_{T}}{\partial x_{i}}=\frac{1}{\tau_{T}}\left(f_{T}^{e}-f_{T}\right)+R_{T}, \\
& \frac{\partial f_{\phi}}{\partial t}+v_{i} \cdot \frac{\partial f_{\phi}}{\partial x_{i}}=\frac{1}{\tau_{\phi}}\left(f_{\phi}^{e}-f_{\phi}\right)+R_{\phi},
\end{aligned}
$$

де $f_{v}, f_{T}, f_{\phi}$ - функції розподілу швидкості, температури та концентрації частинок відповідно, $f_{v}^{e}, f_{T}^{e}, f_{\phi}^{e}-$ рівноважні функції розподілу швидкості, температури та концентрації частинок відповідно, які відповідають рівноважному розподілу Максвелла.

Функція $R_{v}$ описує силу Архімеда та базується на рівняння стану

$\rho=\phi \rho_{p}+(1-\phi) \rho_{f 0}\left(1-\alpha\left(T-T_{r}\right)\right)$,

де $T_{r}$ реперна температура, яка може дорівнювати $T_{1}$ або $T_{2}$.

Функції $R_{T}$ та $R_{\phi}$ описують вплив броунівської дифузії та термофорезу на теплообмін та дифузію.

Моделювання проводилось в двовимірній постановці. Для двовимірних задач зазвичай використовується двовимірна решітка D2Q9 3 дев'ятьма швидкісними каналами. Ініціалізація функцій розподілу швидкості, температури та концентрації частинок провадилась 3 використанням наступних виразів для рівноважного розподілу на решітці D2Q9

$$
\begin{aligned}
& f_{v i}^{e}=w_{i} \rho\left[1+\frac{3\left(e_{i} \cdot u\right)}{c^{2}}+\frac{9\left(e_{i} \cdot u\right)^{2}}{2 c^{4}}-\frac{3 u^{2}}{2 c^{2}}\right], i=0 \div 9 \text {, } \\
& -\frac{3 u^{2}}{2 c^{2}}, i=0 \\
& f_{T i}^{e}=\left\{w_{i} T\left[\frac{3}{2}+\frac{3\left(e_{i} \cdot u\right)}{2 c^{2}}+\frac{9\left(e_{i} \cdot u\right)^{2}}{2 c^{4}}-\frac{3 u^{2}}{2 c^{2}}\right], i=1,2,3,4,\right. \\
& w_{i} T\left[3+\frac{6\left(e_{i} \cdot u\right)}{c^{2}}+\frac{9\left(e_{i} \cdot u\right)^{2}}{2 c^{4}}-\frac{3 u^{2}}{2 c^{2}}\right], i=5,6,7,8 \\
& f_{\phi i}^{e}=\left\{\begin{array}{c}
-\frac{3 u^{2}}{2 c^{2}}, i=0 \\
w_{i} \phi\left[\frac{3}{2}+\frac{3\left(e_{i} \cdot u\right)}{2 c^{2}}+\frac{9\left(e_{i} \cdot u\right)^{2}}{2 c^{4}}-\frac{3 u^{2}}{2 c^{2}}\right], i=1,2,3,4, \\
w_{i} \phi\left[3+\frac{6\left(e_{i} \cdot u\right)}{c^{2}}+\frac{9\left(e_{i} \cdot u\right)^{2}}{2 c^{4}}-\frac{3 u^{2}}{2 c^{2}}\right], i=5,6,7,8
\end{array},\right.
\end{aligned}
$$


де вагові коефіцієнти для кожного напрямку є

$$
w_{i}= \begin{cases}4 / 9, & i=0 \\ 1 / 9, & i=1,2,3,4 . \\ 1 / 36, & i=5,6,7,8\end{cases}
$$

Значення основних макропараметрів течії (густини, швидкості, тиску, енергії та концентрації наночасток) за відомими функціями розподілу для решітки D2Q9 з дев'ятьма швидкісними каналами визначались за наступними виразами $\rho=\sum_{i} f_{v i}$

$\rho u=\sum_{i} \mathrm{v}_{i} f_{v i}$

$p=\frac{1}{3} \sum_{i}\left(\mathrm{v}_{i}-u\right)^{2} f_{v i}, \quad i=0 \div 9$.

$\rho e=\sum_{i} f_{T i}$,

$\rho \phi=\sum_{i} f_{\phi i}$

При моделюванні використовувались наступні граничні умови. На вході та виході каналу задані умови симетрії (нескінченний канал). На стінках - швидкості, що відповідають нерухомій стінці та стінці, що обертається; температури стінок; концентрація наночастинок на стінках відповідає наступному співвідношенню

$$
\left(D_{B} \frac{\partial \phi}{\partial y}\right)_{w}=-\left(\frac{D_{B}}{T_{w}} \frac{\partial T}{\partial y}\right)_{w} .
$$

Перерахунок макропараметрів на границях в функції розподілу імпульсів, енергії та концентрацій виконувався за формулами (2), (3) та (4) відповідно.

\section{Результати та обговорення}

Розрахунки течії нанорідини на основі методу граток Больцмана дозволили отримати незбурені та збурені характеристики гідродинаміки та тепло- і масообміну у зазорі утвореному двома концентричними циліндричними поверхнями 3 внутрішньою поверхнею, що обертається. На рис. 1 показані профілі незбурених швидкості, температури та концентрації наночасток. Цей рисунок демонструє те, що градієнти концентрації та температури мають різні знаки. Це обумовлено взаємодією броунівського і термофоретічного процесів дифузії. При цьому швидкість слабозалежить від наявності наночасток у потоці.

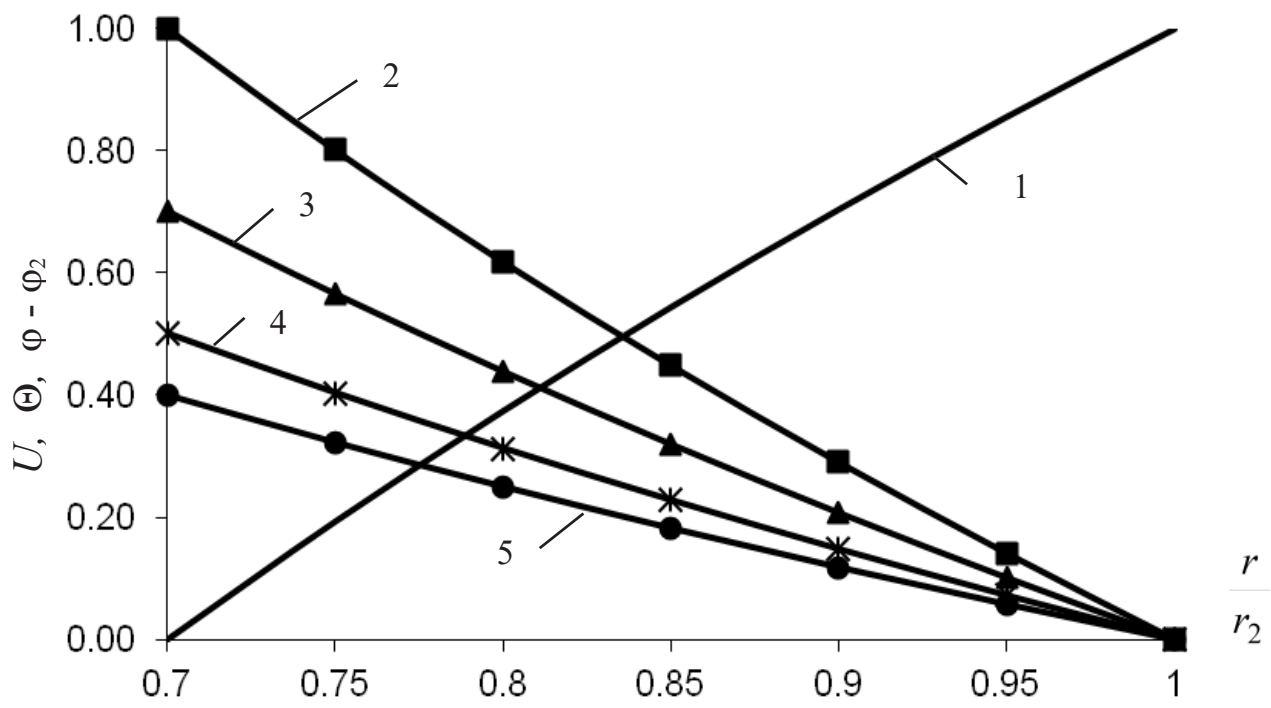

Рис. 1. Профілі незбурених ивидкості, температури та концентрації наночасток: $1-\Theta ; 2-U ; 3-\varphi-\varphi_{2}$ при $(A=0,4), 4-\varphi-\varphi_{2}$ при $(A=0,5) ; 5-\varphi-\varphi_{2}$ при $(A=0,7)$.

При певних значеннях числа Тейлора в потоці можуть розвиватися вихорі, поява яких обумовлена відцентровою нестійкістю. Аналіз показує, що ця нестійкість залежить від безрозмірних комплексів $\eta, N, M, A, \operatorname{Pr}, \mathrm{Sc}$, які можна розписати таким чином:

$$
N=\alpha\left(T_{2}-T_{1}\right) \operatorname{Pr}, \quad M=\frac{\rho_{p}}{\rho_{f 0}}-1,
$$


$\operatorname{Pr}=\frac{\mu(\rho c)_{f 0}}{\rho_{f 0} k}, \quad \mathrm{Sc}=\frac{\mu}{\rho_{f} D_{B}}$,

$\eta=\frac{R_{1}}{R_{2}}, A=\frac{T_{2}-T_{1}}{T_{r}} \frac{D_{T}}{D_{B}}$.

Розглянемо вплив безрозмірних параметрів (9) - (11) на критичне число Тейлора. Розрахун- ки показали, що стійкість потоку зменшується зі збільшенням відносної щільності $M$, яка може бути віднесена до додаткових збурень, які наночастинки вводять в потік. Результати залежності критичного чиста Тейлора від параметра $M$ для різної величини зазору між поверхнями наведено в табл. 1.

Таблиця 1

\begin{tabular}{|c|c|c|c|c|}
\hline$\eta$ & $\mathrm{M}=0$ & $\mathrm{M}=1$ & $\mathrm{M}=2$ & $\mathrm{M}=3$ \\
\hline 0,99 & 48,75 & 40,84 & 35,39 & 32,27 \\
\hline 0,95 & 50,16 & 41,84 & 36,61 & 33,07 \\
\hline 0,7 & 63,25 & 51,21 & 44,1 & 37,31 \\
\hline 0,5 & 86,21 & 66,45 & 56,49 & 11,4 \\
\hline 0,3 & 152,79 & 109,21 & 89,03 & 76,95 \\
\hline 0,1 & 460 & 406,65 & 302,91 & 232,174 \\
\hline
\end{tabular}

Відносне зниження критичного числа Тейлора послаблюється зі збільшенням температури нерівномірності. Вплив комплексів $M$ і $N$ на критичне число Тейлора має дві протилежні тенденції: параметр $N$ супроводжується стабілізуючим впливом, а параметр $M$ вносить дестабілізуючий ефект. Після того, як параметр $N$ стає позитивним, обидва комплекси діють в тому ж напрямку, і ефект параметра $M$ стає слабкішим при збільшенні значень параметра $N$. Це було прийнято до уваги під час розрахунків, зміна знака параметра $M$ викликає відповідну зміну знака параметра $A$. Слід також зазначити, що вплив параметра $M$ послаблюється через зменшення відносної ширини радіального зазору. Це пояснюється тим, що при великих значеннях $\eta$ потік набагато більш нестабільний, ніж для низьких значень $\eta$.

Вплив параметра $A$ на характер відцентрової нестійкості можна описати таким чином: потік стає менш стабільним при більш високих значеннях параметра $A$, тобто після інтенсифікації термічної дифузії, котра, в свою чергу визначається ступенем температурної нерівномірності. Проте, відносна ступінь впливу термодифузії послаблюється зі збільшенням температурної нерівномірності, та зі зменшенням радіального зазору. Це передбачає формальну аналогію між впливом параметрів $M$ i $A$ на значення критичних чисел Тейлора.

Вплив числа Прандтля на відцентрову нестійкость проявляється по-різному для випадків стійких $(N<0)$ і нестійких $(N>0)$ температурних градієнтів. При негативному температурному градієнті критичне число Тейлора збільшується зі збільшенням числа Прандтля, тобто потік стає більш стійким. У разі позитивних температурних градієнтів, збільшення числа Прандтля призводить до втрати стійкості течії. Ця тенденція може бути пов'язана з ефектом теплопровідності, який з'являється в знаменнику числа Прандтля. Для $N<0$ збільшення числа Прандтля може бути викликане зниженою теплопровідністю, що додатково призводить до зниження температури в безпосередній близькості від увігнутої поверхні. Це, в свою чергу, тягне за собою збільшення щільності нанорідини i, отже, збільшення критичних значень числа Тейлора. Для $N>0$ зменшення теплопровідності зменшує швидкість зниження температури біля увігнутої стінки, яка викликає зниження щільності і відповідно дестабілізує потік. Вплив числа Прандтля на критичне число Тейлора послаблює в невеликих радіальних зазорах як позитивні, так і негативні температурні градієнти.

Розрахунки показали, що більш високі числа Шмідта викликали зниження стабільності потоку і для позитивних і негативних температурних 
градієнтів. Це, вочевидь, обумовлено зменшенням коефіцієнта дифузії $D_{B}$, який призводить до зниження рухливості наночастинок, що в свою чергу призводить до втрати стійкості потоку. Цей висновок узгоджується з тенденціями, виявленими у дослідженні впливу параметрів $M$ і $A$ на критичне число Тейлора.

Зменшення відносного критичного числа Тейлора є досить різким, поки число Шмідта не досягає значення $\mathrm{Sc} \approx 500$. Потім зниження критичного числа Тейлора сповільнюється і приймає лінійну форму. В обох випадках вплив градієнта температури на відносне критичне число Тейлора $\epsilon$ незначним.

\section{Висновки}

В роботі вивчалася гідродинаміка, тепло- i масообмін та відцентрова нестабільність потоку нанорідин між двома концентричними циліндрами, один з яких обертається за умови радіальних градієнтів температури і концентрації в нанорідині. Задача вирішена чисельно за допомогою методу решіток Больцмана. Результати обчислень визначили вплив таких факторів, як радіальна ширина зазору (параметр ๆ), температурний градієнт (параметр $N$ ), відношення густин наночастинок і рідини (параметр $M$ ), вплив Броунівської і термофоретічної дифузії (параметр $A$ ), а також чисел Прандтля і Шмідта. Ці дослідження показали, що вплив всіх параметрів на стабільність зменшується зі зменшенням ширини радіального зазору. Від'ємні температурні градієнти сприяють стабілізації потоку, в той час як позитивні температурні градієнти дестабілізують його. Збільшення параметрів $M, A$ i Sc дестабілізує течію і у випадках позитивних і від'ємних температурних градієнтів. Більш високі числа Прандтля стабілізують потік при від'ємних температурних градієнтах і дестабілізують його за умови позитивних температурних градієнтів.

\section{ЛІТЕРАТУРА}

1. Wenhua Y., France D.M. Routbort J.L., Choi S.U.S. Review and comparison of nanofluid thermal conductivity and heat transfer enhancements // Heat Transfer Eng.. - 2008. V. 29, № 5. - P. 432-460.

2. Das S.K., Choi S.U.S., Patel H.E. Heat transfer in nanofluids: A review // Heat Transfer Eng. -2006.
- V. 27. - P. 3 - 19.

3. Kakas K.S., Pramuanlaroenkij A. Review of convective heat transfer enhancment with nanofluids // Int. J. Heat Mass Transfer. - 2009. - V. 52. P. $3187-3196$.

4. Buschman M.H. Nanofluids in thermosyphons and heat pipes: Overview of recent experiments and modelling approaches // Int. J. Therm. Sci. - 2013. V. $72 .-$ P. $1-17$.

5. Huming G., Huming A. Heat transfer characteristics of a two-phase closed thermosyphons using nanofluids // Exp. Thermal Fluid Sci. - 2011. V. 35, № 3. - P. $550-557$.

6. Lai $W$. Stability of a revolution fluid with variable density in the presence of a circular magnetic fluid // Physics of Fluids - 1962. - V. 25. P. $560-566$.

7. Avramenko A.A., Blinov. D.G., Shevchuk I.V. Self-similar analysis of fluid flow and heat-mass transfer of nanofluids in boundary layer // Phys. Fluids. - 2011. - V. 23. P. 082002.

8. Avramenko A.A., Blinov. D.G., Shevchuk I.V., Kuznetsov A.V. Symmetry analysis and self-similar forms of fluid flow and heat-mass transfer in turbulent boundary layer flow of a nanofluid // Phys. Fluids. - 2012. -V. 24. P. 092003.

9. Avramenko A.A., Tyrinov A.I. Heat transfer at film condensation of stationary vapor with nanoparticles near a vertical plate // Appl. Therm. Eng. - 2014. - V.73, №. 1. - P. 389 - 396.

10. Avramenko A.A., Tyrinov A.I., Shevchuk I.V., Blinov. D.G. Heat transfer at film condensation of moving vapor with nanoparticles over a flat surface // Int. J. Heat Mass Transf. - 2015a. - V. 82. P. 316-324.

11. Avramenko A.A., Tyrinov A.I., Shevchuk I.V., Blinov. D.G. Heat transfer in stable film boiling of a nanofluid over a vertical surface // Int. J. Therm. Sci. - 2015b. - V. 92. - P. 106-118.

12. Fedele L., Colla L., Bobbo S., Barison S., Agresti F. Experimental stability analysis of different water-based nanofluids // Nanoscale Research Letters - 2011. - V. 6. - P. 300.

13. Joni I.M., Purwanto A., Iskandar F., Okuyama $K$. Dispersion stability enhancement of titania nanoparticles in organic solvent using a bead mill process // Ind. Eng. Chem. Res. - 2009. - V.48, № 15 . - P. 6916-6922. 
14. Walowit J., Tsao.S., Diprima R. Stability of flow between arbitrarily spaced concentric cylindrical surfaces including the effect of a radial temperature gradient // J. Appl. Mech. - 1964. V. 30, № 4. - P. 585-593.

15. Mutabazi I., Gullerm R., Prigent A., Lepiller $V$., Malik $S$. Flow instabilities in a vertical differentially rotating cylindrical annulus with a radial temperature gradient // EUROMECH Colloquium. 2011, - 21-23 June. V.52. - P. 300.

16. Pak. B.C., Cho Y.I. Hydrodynamic and heat transfer study of dispersed fluids with submicron metallic oxide particles // Exp. Heat Transfer. - 1998.

\section{THE APPLICATION OF LATTICE BOLTZMANN TO FLOW ANALYSIS NANOFLUID IN THE CHANNEL BETWEEN COAXIAL CYLINDERS}

\section{Avramenko A.O., Tyrinov A.I., Dmytrenko N.P., Kravchuk O.V.}

Institute of Engineering Thermophysics of the National Academy of Sciences of Ukraine, vul. Zhelyabova, 2a, Kyiv, 03680 Ukraine

In this paper hydrodynamics, heat and mass transfer and centrifugal instability nanofluids flow between two concentric cylinders, one of which revolves provided radial gradients of tem-perature and concentration nanofluid are studied. The problem is solved numerically using the method of Lattice Boltzmann Method.

Key words: nanofluid, centrifugal instability, curvilinear channel, heat- masstransfer, TaylorCouette flow.

References 19, figures 1, tables 1 .
- V. 11. - P. 151-170.

17. Brian J. N. Application of two-dimensional cellular automaton lattice-gas models to the simulation of hydrodynamics / J. N. Brian. - University of Edinburgh. 1990. -190 p.

18. Maxwell J.B. Lattice Boltzmann methods for interfacial wave modelling. - University of Edinburgh. 1997. $-238 \mathrm{p}$.

19. P.L. Bhatnagar, E.P. Gross, M. Krook. A Model for Collision Processes in Gases. I. Small Amplitude Processes in Charged and Neutral OneComponent Systems // Physical Review. 1954. V.94. P. 511-525.

1. Wenhua Y., France D.M. Routbort J.L., Choi S.U.S. Review and comparison of nanofluid thermal conductivity and heat transfer enhancements // Heat Transfer Eng.. - 2008. V. 29, № 5. - P. 432-460.

2. Das S.K., Choi S.U.S., Patel H.E. Heat transfer in nanofluids: A review // Heat Transfer Eng. -2006. - V. 27. - P. 3-19.

3. Kakas K.S., Pramuanlaroenkij A. Review of convective heat transfer enhancment with nanofluids // Int. J. Heat Mass Transfer. - 2009. - V. 52. P. $3187-3196$.

4. Buschman M.H. Nanofluids in thermosyphons and heat pipes: Overview of recent experiments and modelling approaches // Int. J. Therm. Sci. - 2013. V. 72. - P. 1-17.

5. Huming G., Huming A. Heat transfer characteristics of a two-phase closed thermosyphons us-ing nanofluids // Exp. Thermal Fluid Sci. -2011. V. 35, № 3. - P. 550-557.

6. Lai $W$. Stability of a revolution fluid with variable density in the presence of a circular magnetic fluid // Physics of Fluids - 1962. - V. 25. - P. 560 $-566$.

7. Avramenko A.A., Blinov. D.G., Shevchuk I.V. 
Self-similar analysis of fluid flow and heat-mass transfer of nanofluids in boundary layer // Phys. Fluids. - 2011. - V. 23. P. 082002.

8. Avramenko A.A., Blinov. D.G., Shevchuk I.V., Kuznetsov A.V. Symmetry analysis and self-similar forms of fluid flow and heat-mass transfer in turbulent boundary layer flow of a nanofluid // Phys. Fluids. - 2012. -V. 24. P. 092003.

9. Avramenko A.A., Tyrinov A.I. Heat transfer at film condensation of stationary vapor with nanoparticles near a vertical plate // Appl. Therm. Eng. - 2014. - V.73, №. 1. - P. 389-396.

10. Avramenko A.A., Tyrinov A.I., Shevchuk I.V., Blinov. D.G. Heat transfer at film condensation of moving vapor with nanoparticles over a flat surface // Int. J. Heat Mass Transf. - 2015a. - V. 82. P. 316-324.

11. Avramenko A.A., Tyrinov A.I., Shevchuk I.V., Blinov. D.G. Heat transfer in stable film boiling of a nanofluid over a vertical surface // Int. J. Therm. Sci. - 2015b. - V. 92. - P. 106-118.

12 Fedele L., Colla L., Bobbo S., Barison S., Agresti F. Experimental stability analysis of different water-based nanofluids // Nanoscale Research Letters - 2011. - V. 6. - P. 300.

13. Joni I.M., Purwanto A., Iskandar F., Okuyama $K$. Dispersion stability enhancement of titania nanoparticles in organic solvent using a bead mill process // Ind. Eng. Chem. Res. - 2009. - V.48, № 15. - P. 6916-6922.

14. Walowit J., Tsao.S., Diprima R. Stability of flow between arbitrarily spaced concentric cylindrical surfaces including the effect of a radial temperature gradient // J. Appl. Mech. - 1964. V. 30, № 4. - P. 585-593.

14. Mutabazi I., Gullerm R., Prigent A., Lepiller $V$., Malik $S$. Flow instabilities in a vertical differentially rotating cylindrical annulus with a radial temperature gradient // EUROMECH Colloquium. 2011, - 21-23 June. V.52. - P. 300.

16. Pak. B.C., Cho Y.I. Hydrodynamic and heat transfer study of dispersed fluids with submi-cron metallic oxide particles // Exp. Heat Transfer. - 1998. - V. 11. - P. 151-170.

17. Brian J.N. Application of two-dimensional cellular automaton lattice-gas models to the simulation of hydrodynamics / J. N. Brian. - University of Edinburgh. 1990. -190 p.

18. Maxwell J.B. Lattice Boltzmann methods for interfacial wave modelling. - University of Edinburgh. 1997. $-238 \mathrm{p}$.

19. P.L. Bhatnagar, E.P. Gross, M. Krook. A Model for Collision Processes in Gases. I. Small Amplitude Processes in Charged and Neutral OneComponent Systems // Physical Review. 1954. V.94. P. 511-525.

Получено 25.02.2016 Received 25.02.2016 